\title{
Bioanalysis of Febuxostat in Human Plasma by Liquid Chromatography/Tandem Mass Spectrometry
}

\author{
Surya Prakasarao Kovvasu ${ }^{3,4}$, Steven Yeung ${ }^{4}$, \\ Priyanka Kunamaneni $^{4}$, Balaji Kodali ${ }^{1,2 *}$ \\ ${ }^{* 1}$ AxisClinicalsLimited, Miyapur, Hyderabad-500049,Telangana, India. \\ ${ }^{2}$ University College of Pharmaceutical Sciences, Acharya Nagarjuna University, \\ Nagarjuna Nagar, Guntur- 522510, Andhra Pradesh, India. \\ ${ }^{3}$ University College of Pharmaceutical Sciences,Andhra University, Visakhapatnam- \\ 530 003, Andhra Pradesh, India. \\ ${ }^{4}$ College of Pharmacy, Western University of Health Sciences, Pomona, CA 91766, \\ United States.
}

\begin{abstract}
The objective of this paper was to describe the development and validation of a novel liquid chromatography / tandem mass spectrometry (LC-MS/MS) method for the determination of Febuxostat in human plasma using febuxostat-d9 as internal standard (IS). An API-4000 triple quadrupole mass spectrometer operated in MRM mode was used for the selective quantification of Febuxostat in human plasma. Sample extraction utilizes protein precipitation (PP), followed by analyte and the IS were chromatographed on a C18 column using an isocratic mobile phase composed of $5 \mathrm{mM}$ ammonium formate and acetonitrile $(20: 80, \mathrm{v} / \mathrm{v})$ pumped at a flow rate of $1.0 \mathrm{~mL} / \mathrm{min}$. Precision and accuracy of the method was determined using five analytical batches in the concentration range of $15.0-8000 \mathrm{ng} / \mathrm{mL}$. All the validation experiments were carried out as per the US FDA guidelines and results met the acceptance criteria. The developed method was rapid with a total chromatographic run time of $2.0 \mathrm{~min}$.
\end{abstract}

Keywords : Febuxostat; Human plasma; Method validation; LC-MS/MS.

\section{Introduction}

Febuxostat is used for the treatment of gout and hyperuricemia. It inhibits xanthine oxidase, thus reducing production of uric acid in the body ${ }^{[1,2]}$. Febuxostat was well tolerated at once-daily doses of 10-240 mg. Febuxostat on oral administration, rapidly absorbed and reach maximum plasma concentration around 0.5$1.3 \mathrm{~h}$. Febuxostat was extensively metabolised and renal function did not seem to play an important role in its elimination from the body ${ }^{[3]}$. It was approved by US FDA in the year of 2009 . The drug was also approved in China and EU recommended at $40 \mathrm{mg}$ or $80 \mathrm{mg}$ once daily ${ }^{[4]}$. 
Few LC-MS/MS methods ${ }^{[5-8]}$ have been reported for Febuxostat quantification in plasma. The author Vakaet al., $2013^{[5]}$ published a method for the determination of febuxostat in human plasma with a run time of $>5$ min. Similarly, Lukram et al., $2012^{[6]}$ reported an UPLC-MS/MS for the Febuxostat in human plasma with an LLOQ of $0.075 \mu \mathrm{g} / \mathrm{mL}$. Both the methods have utilized liquid-liquid extraction (LLE) technique for sample preparation. Moreover, Lukram et al., 2012 employs a volume of $500 \mu \mathrm{L}$ plasma for sample preparation, which is relatively high volume for a routine bioequivalence studies. The author'sWang et al., $2013^{[7]}$ and Ding et al., $2012^{[8]}$ described a LC-MS/MS method for the determination of febuxostat in plasma but both the methods employed protein precipitation (PP) technique for the sample preparation with chromatographic run time of $>4$ min. An effective bioanalytical method should be simple, sensitive, reproducible, rapid (short analytical run time) and it should require low sample volume for sample processing ${ }^{[9,10]}$.

The current paper described in detail about the LC-MS/MS method development and validation for the quantification of febuxostat in human plasma using febuxostat-d9 as internal standard (IS). The deuterated IS which mimics the behavior as like analyte (congener) in terms of ionization and extraction. The congener behavior nullifies the matrix effect. A simple protein precipitation (PP) was used to extract the analyte and IS from plasma. No significant interference was observed at the retention time of analyte and IS with proposed method conditions.

\section{Materials and Methods}

\section{Standards and reagents}

The working standards of febuxostat (99.6\%) and febuxostat-d9 (Fig.1) (99.4\%) were obtained from Vivan Lifesciences Limited (Mumbai, India). HPLC grade acetonitrile and methanol were purchased from J.T. Baker (Phillipsburg, NJ, USA), while analytical grade ammonium formate was obtained from Merck Ltd (Mumbai, India). LC-MS grade water was collected by using Milli Q water purification system procured from Millipore (Bangalore, India). The drug free $\mathrm{K}_{2}$ human plasma was obtained from Deccan's Pathological Lab's (Hyderabad, India).<smiles>Cc1nc(-c2ccc(OCC(C)C)c(C#N)c2)sc1C(=O)O</smiles>

\section{Febuxostat}<smiles>[2H]C([2H])([2H])C([2H])(C([2H])([2H])[2H])C([2H])([2H])Oc1ccc(-c2nc(C)c(C(=O)O)s2)cc1C#N</smiles>

Febuxostat-d9 (IS)

Figure 1: Chemical structure of Febuxostat and febuxostat-d9 (IS). 


\section{LC-MS/MS instrument conditions}

An API-4000 (MS/MS) (AB Sciex, Foster City, CA, USA) triple quadrupole mass spectrometer equipped with a Turbo ion spray ${ }^{\mathrm{TM}}$ in positive ion mode was used for the quantification. The mass spectrometer was coupled with HPLC system (Shimadzu, Kyoto, Japan). An aliquot of $10 \mu \mathrm{L}$ of the processed sample was injected into the column (Kromasil 100-5C18, $100 \mathrm{~mm} \times 4.6 \mathrm{~mm}, 5 \mu \mathrm{m}$ ), maintained at ambient $\left(25 \pm 2^{\circ} \mathrm{C}\right)$ temperature. A mixture of $5 \mathrm{mM}$ ammonium formate and acetonitrile $(20: 80, \mathrm{v} / \mathrm{v})$ was used to separate the analyte from interferences. The mobile phase was pumped at a flow rate of $0.8 \mathrm{~mL} / \mathrm{min}$. Mass spectrometer was maintained with interface temperature $500{ }^{\circ} \mathrm{C}$ and ion spray voltage was set at $5000 \mathrm{~V}$. Detection of the ions was carried out in the multiple-reaction monitoring (MRM) mode, by monitoring the transition pairs of $\mathrm{m} / \mathrm{z}$ 317.1 precursor ion to the $\mathrm{m} / \mathrm{z} 261.0$ product ion for febuxostat and $\mathrm{m} / \mathrm{z} 326.1$ precursor ion to the $\mathrm{m} / \mathrm{z} 262.0$ product ion for the IS. Quadrupoles (Q1 and Q3) were operated in unit resolution. The source parameters viz. the nebulizer gas (GS1), auxiliary gas (GS2), curtain gas and collision gas were set at 40, 40, 35, and $10 \mathrm{psi}$, respectively. The voltage values for declustering potential (DP), collision energy (CE), entrance potential (EP) and collision cell exit potential (CXP) were set at 50,26, 10,11 V for febuxostat and for the IS. The data acquisition was performed by using Analyst software ${ }^{\mathrm{TM}}$ (version 1.4.2).

\section{Preparation of calibration standards and quality control samples}

All stock solutions were prepared in methanol at a concentration of $1 \mathrm{mg} / \mathrm{mL}$ and respective working solutions were prepared using diluent (water and methanol 70:30, v/v). The spiked samples were prepared in the linear range of 15-8000 ng/mL in plasma. The five QC concentrations were prepared at $15.1 \mathrm{ng} / \mathrm{mL}$ (lower limit of quantitation quality control, LLOQ QC), $50.0 \mathrm{ng} / \mathrm{mL}$ (low quality control, LQC), $1200 \mathrm{ng} / \mathrm{mL}$ (medium quality control, MQC1), $4000 \mathrm{ng} / \mathrm{mL}$ (MQC2) and $6000 \mathrm{ng} / \mathrm{mL}$ (high quality control, HQC).

\section{Extraction procedure}

A $250 \mu \mathrm{L}$ aliquot of human plasma sample was mixed with $25 \mu \mathrm{L}$ of the internal standard working solution $(10.0 \mu \mathrm{g} / \mathrm{mL}$ of febuxostat-d9). To this, $100 \mu \mathrm{L}$ of $0.1 \%$ formic acid $(5 \% \mathrm{v} / \mathrm{v})$ was added after vortex mixing for $10 \mathrm{~s}$. Then the samples were precipitated with $1 \mathrm{~mL}$ of acetonitrile. After vortex-mixing for $30 \mathrm{~s}$ and centrifugation at $4000 \mathrm{rpm}$ for $20 \mathrm{~min}$, the supernatant was transferred to glass test tubes and evaporated under gentle stream of nitrogen ( $20 \mathrm{psi}$ ) at $45^{\circ} \mathrm{C}$ and samples were reconstituted with $500 \mu \mathrm{L}$ of mobile phase. The reconstituted solution was transferred into $1 \mathrm{~mL}$ vials.

\section{Method validation}

The proposed method was validated for selectivity, sensitivity, matrix effect, linearity, precision and accuracy, dilution integrity, recovery, and stability as per the current US FDA guidelines ${ }^{[1]}$.

\section{Results and Discussion}

\section{Method development}

API-4000 mass spectrometry conditions (source dependent and compound dependent) were optimized using $100 \mathrm{ng} / \mathrm{mL}$ working solution of analyte and the IS. We found more intense peaks in positive mode when compare to the negative mode using ESI source. MRM technique was used to monitor the ions for better selectivity and specificity ${ }^{[12-15]}$. Mass spectrometry source and compound dependent parameters were suitably tuned to get better intense signals and reproducible response. From the MSMS spectrum of analyte and IS in positive ion mode, the transition pairs of $\mathrm{m} / \mathrm{z} 317.1$ precursor ion to the $\mathrm{m} / \mathrm{z} 261.0$ product ion for febuxostat and $\mathrm{m} / \mathrm{z} 326.1$ precursor ion to the $\mathrm{m} / \mathrm{z} 262.0$ product ion for the IS were selected to monitor in MRM. The chemical structures of febuxostat and febuxostat-d9 were shown in Fig. 1.

HPLC conditions were optimized by using a variety of volatile buffers ammonium formate, ammonium acetate, as well as acid additives like formic acid and acetic acid at different strength in mobile phase to achieve highest sensitivity. Also, a variety of columns like $\mathrm{C}_{18}$ and $\mathrm{C}_{8}$ of different makes were checked for good peak shape and for better selectivity. Finally, the mobile phase composed of $5 \mathrm{mM}$ ammonium formate and acetonitrile $(20: 80, \mathrm{v} / \mathrm{v})$ gives better peak shape with a Kromasil 100-5C18 $(100 \times 4.6,5 \mu \mathrm{m})$ column. The 
mobile phase was pumped at a flow rate of $0.8 \mathrm{~mL} / \mathrm{min}$ and the analyte and the IS were retained at about 1.25 min with total analytical run time of 2 min.

Initially we tested a variety of extraction techniques like PP, SPE and LLE. SPE was tested with Starata $\mathrm{X}$ polymeric sorbent, Oasis HLB, Bond ElutPlexa and Orpheus $\mathrm{C}_{18}$, and LLE was tried with hexane, MTBE, ethyl acetate and diethyl ether. Both SPE and LLE methods gave good recovery (>80\%) for the analyte and the IS. But the SPE cartridges are expensive and require special SPE equipment to process the samples. Similarly, LLE requires more non-polar solvents, which involves drying and evaporation. As a purpose to develop a simple and inexpensive extraction method PP was tested with acetonitrile and methanol. Acetonitrile gives clear precipitation and more recovery than the methanol, hence we used for the present purpose. Addition of formic acid helped to obtain high and reproducible recovery for the analyte. Deuterated compounds as internal standard limit the possible matrix suppression or enhancement effect and increases the bioanalytical assay precision and accuracy. Hence, in the present work febuxostat stable labeled isotope febuxostat-d9 was used as an internal standard.

\section{Linearity, precision and accuracy}

The proposed method was validated in the concentration range of $15-8000 \mathrm{ng} / \mathrm{mL}$. A total of five calibration curves were analyzed. Each curve contains blank, blank sample with the IS, 8 non-zero calibration standards and 6 sets of each QCs (LLLOQ QC, LQC, MQC1, MQC2 and HQC). The correlation coefficient value was $>0.99$ during entire course of validation.

Intra-day and inter-day precision and accuracy results of febuxostat for five analytical runs in spiked quality control samples are summarized in Table 1 . Accuracy values were $\pm 15 \%$ of their nominal values and the precision was $<15 \%$. The chromatograms of blank plasma, blank plasma along with IS and extracted LLOQ samples were shown in Fig:2-4.

Table 1: Precision and accuracy data for febuxostat.

\begin{tabular}{|c|c|c|c|c|}
\hline $\begin{array}{l}\text { Quality } \\
\text { control }\end{array}$ & Run & $\begin{array}{l}\text { Concentration found } \\
M e a n \pm S D(n g / m L)\end{array}$ & Precision $(\%)$ & $\operatorname{Accuracy}(\%)$ \\
\hline \multicolumn{5}{|c|}{ Intra-day variations ( $n=12$ at each concentration) } \\
\hline LLOQ & & $16.1 \pm 0.71$ & 4.42 & 107.0 \\
\hline LQC & & $44.8 \pm 1.22$ & 2.72 & 89.6 \\
\hline MQC1 & & $1149 \pm 50.0$ & 4.36 & 95.7 \\
\hline MQC2 & & $3729 \pm 166.0$ & 4.46 & 93.2 \\
\hline $\mathrm{HQC}$ & & $5765 \pm 85.7$ & 1.49 & 96.1 \\
\hline \multicolumn{5}{|c|}{ Inter-day variations ( $n=30$ at each concentration) } \\
\hline LLOQ & & $15.8 \pm 0.74$ & 4.71 & 105.0 \\
\hline LQC & & $44.9 \pm 1.93$ & 4.29 & 89.9 \\
\hline MQC1 & & $1171 \pm 44.6$ & 3.81 & 97.6 \\
\hline MQC2 & & $3776 \pm 153.0$ & 4.04 & 94.4 \\
\hline HQC & & $5751 \pm 117.0$ & 2.03 & 95.8 \\
\hline \multicolumn{5}{|c|}{$\begin{array}{l}\text { Nominal concentrations of LLOQ, LQC, MQC1, MQC2 and HQC are 15.1, 50.0, 1200, } 4000 \\
\text { and } \\
6000 \mathrm{ng} / \mathrm{mL} \text {, respectively. }\end{array}$} \\
\hline
\end{tabular}




\section{Blank - Febuxostat (Doubje Blank) 317.1/261.0 amu}

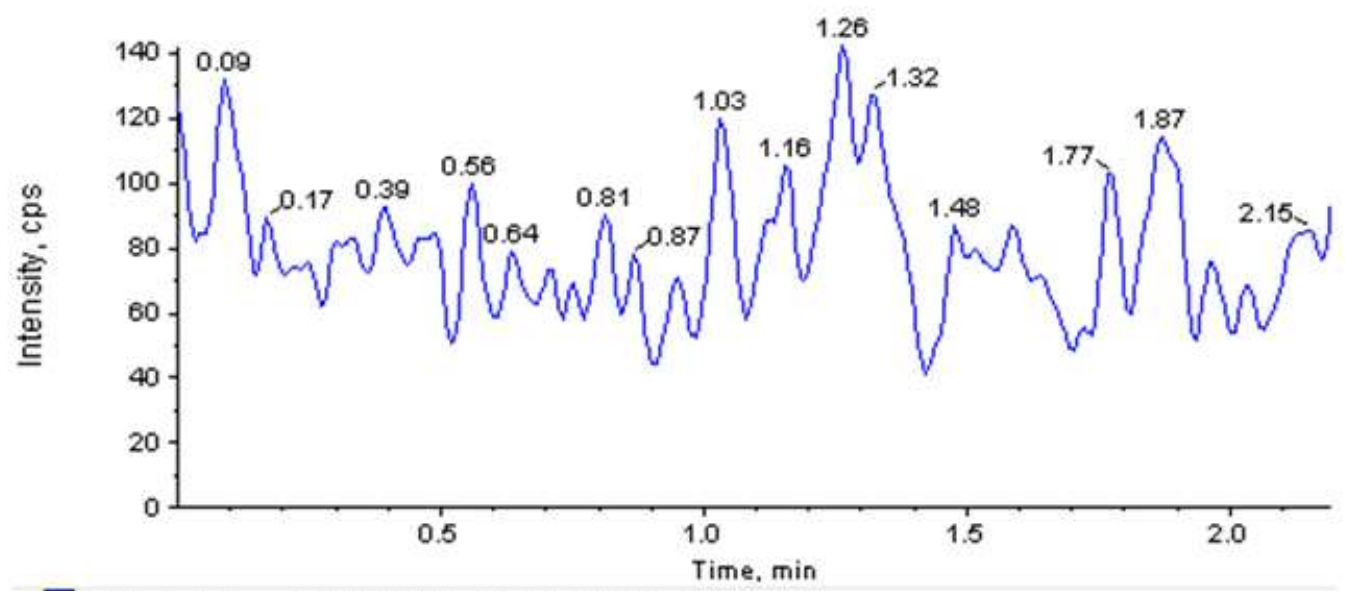

Blank - Febuxostat D9(IS) (Double Blank) $326.1 / 262.0 \mathrm{amu}$

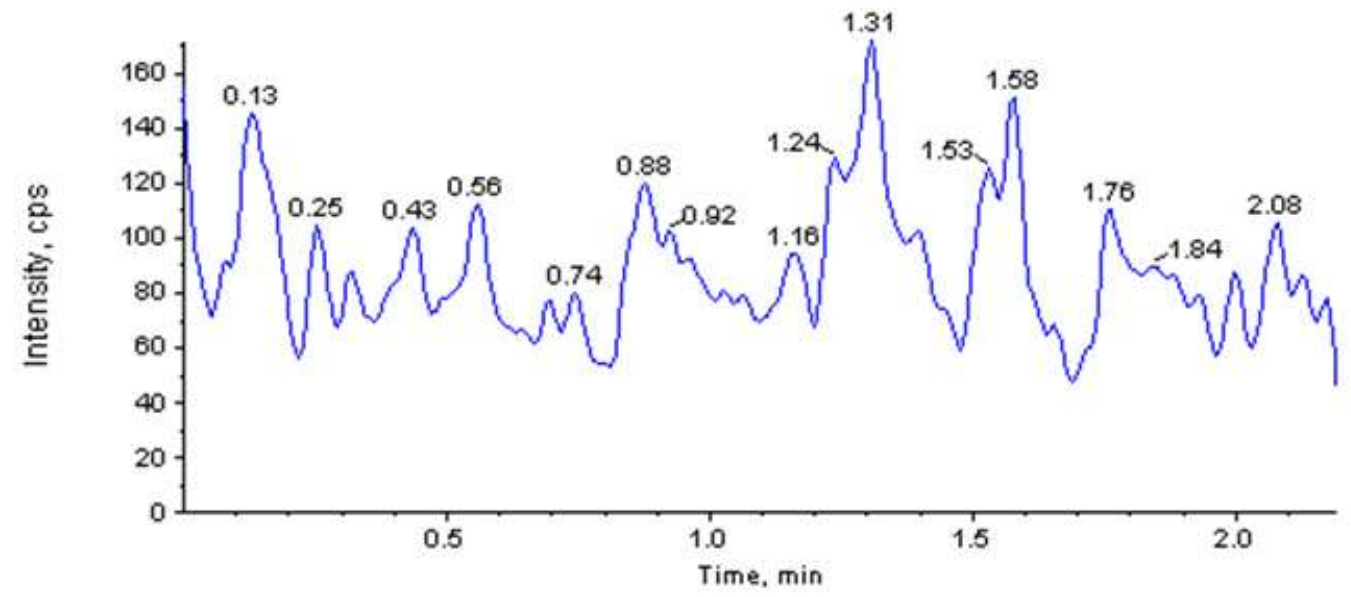

Figure 2: Typical MRM chromatogram of febuxostat and IS in human blank plasma. 


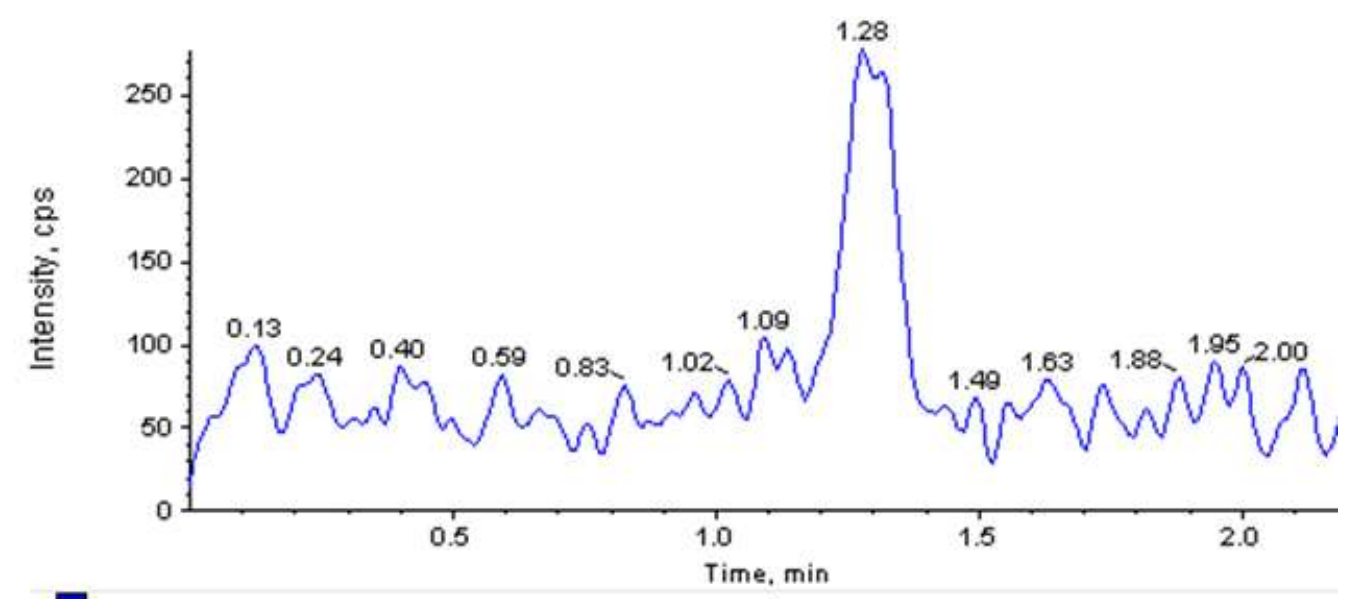

Blank+1S - Febuxostat DQ(IS) (Blank) $326.1 / 262.0$ amu

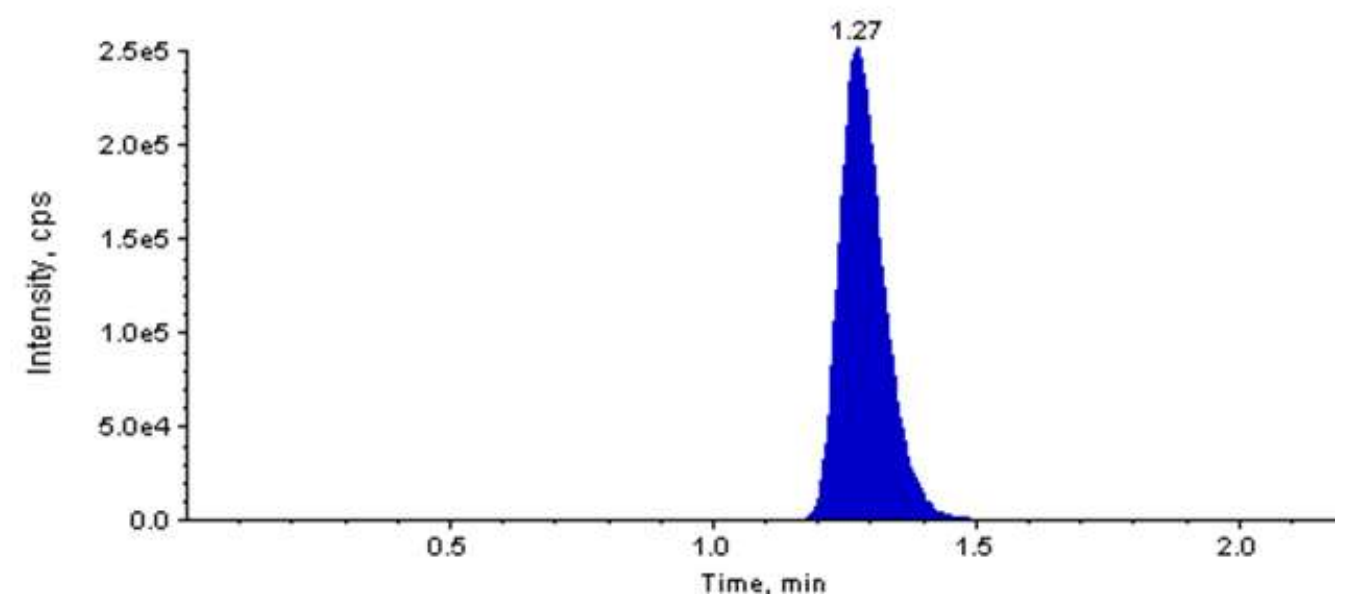

Figure 3: Typical MRM chromatogram of febuxostat and IS in human plasma spiked with IS. 

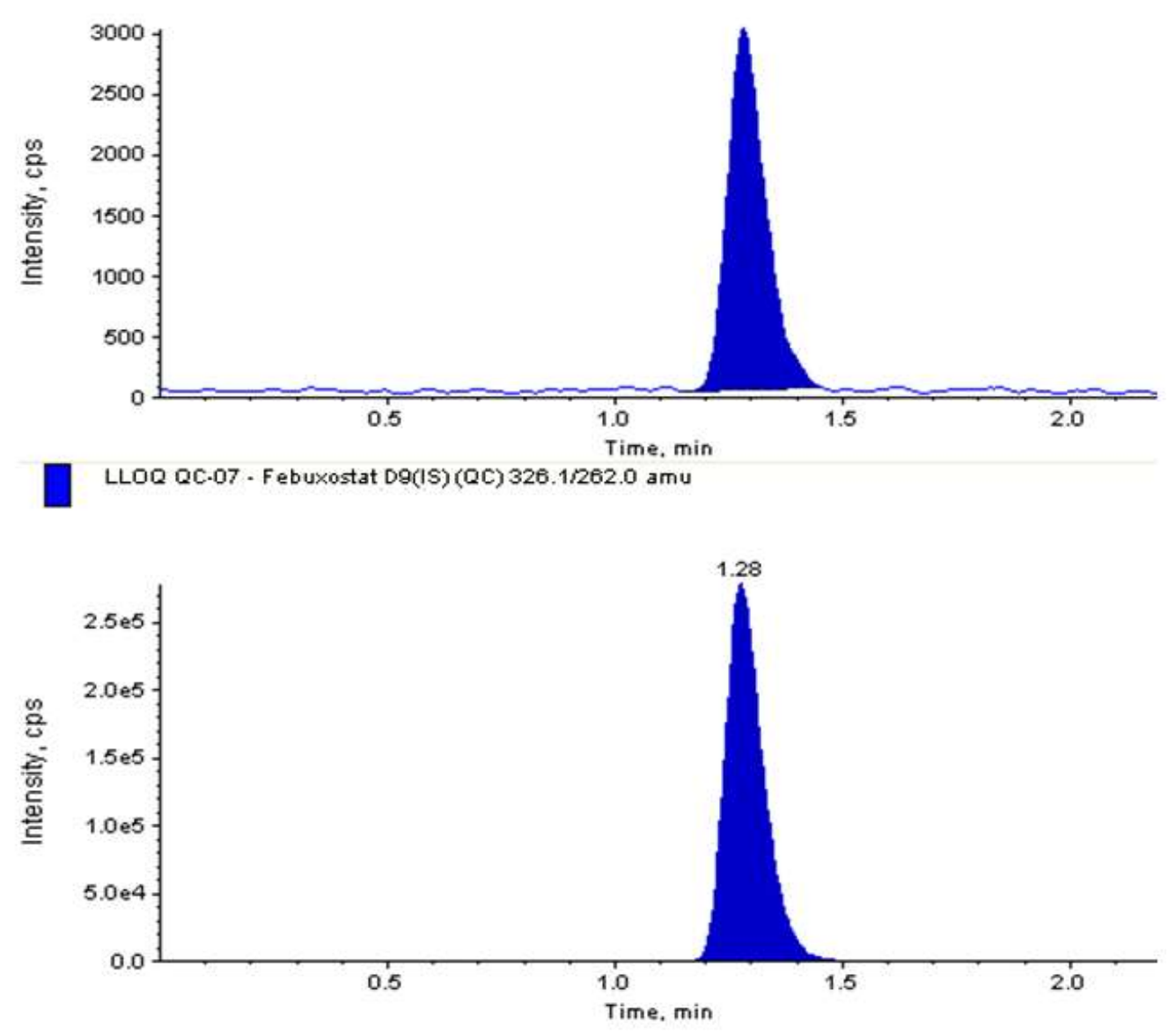

Figure 4: Typical MRM chromatogram of febuxostat and IS in human plasma at LLOQ level.

\section{Chromatography, selectivity and sensitivity}

Analyzed six blank plasma samples obtained from different sources and all are found to be free from significant interference from endogenous components at the RT of analyte and the IS. Also, no cross talk was found from the IS at the RT of analyte. Similarly, no interference was found from OTC drugs like paracetamol, ibuprofen, caffeine, pantoprazole, dicyclomine etc.

The signal-to-noise ratio ( $\mathrm{S} / \mathrm{N})$ was measured at a concentration of $15 \mathrm{ng} / \mathrm{mL}$, which is set as a lowest limit of reliable quantification (LLOQ) for the analyte. The $\mathrm{S} / \mathrm{N}$ ratio at this concentration was found to be $\geq 5$. The precision and accuracy at LLOQ concentration were found to be $6.23 \%$ and $101 \%$, respectively. An LLOQ sample of analyte along with the IS was presented.

\section{Dilution integrity}

The ULOQ value for the present method is $8000 \mathrm{ng} / \mathrm{mL}$, and this can be extended $(16000 \mathrm{ng} / \mathrm{mL})$ by sample dilution with blank plasma. Half (1:2) or quarter (1:4) dilution was performed and quantified under undiluted calibration curve. The precision $(\% \mathrm{CV})$ for dilution integrity of half and quarter dilution was found to be $4.74 \%$ and $2.38 \%$ and the accuracy results were found to be $98.5 \%$ and $98.9 \%$, respectively.

\section{Extraction efficiency}

Simple precipitation with acetonitrile gives highest and reproducible recovery for the analyte and the IS. The mean overall recovery obtained for febuxostat was $80.1 \pm 0.85 \%$ with the precision $(\% \mathrm{CV})$ range of $1.47 \%-12.3 \%$ and the recovery of the IS was $75.4 \%$. 


\section{Matrix effect}

The calculated IS normalised matrix factor values were in the range of 0.9-1.2 at LQC, HQC level indicates there was no significant matric effect. The $\% \mathrm{CV}$ was found to be $<6 \%$.

\section{Stability studies}

The mean $\%$ nominal values were found to be within $\pm 15 \%$ of the predicted concentrations for the analyte at their LQC and HQC levels and the precision (\% CV) values were within 15\% (Table 2) for all the stability tests carried out during the entire course of method validation. All the above stability results were found to be within the acceptable limits during the entire validation.

Table 2: Stability data for febuxostat in plasma $(n=6)$.

\begin{tabular}{|c|c|c|c|c|}
\hline Stability test & $\begin{array}{l}\text { QC (spiked } \\
\text { concentration, } \\
\text { ng/mL) } \\
\end{array}$ & $\begin{array}{l}\text { Mean } \pm \text { SD } \\
(\mathrm{ng} / \mathrm{mL})\end{array}$ & $\begin{array}{l}\text { Precision } \\
(\%)\end{array}$ & $\begin{array}{l}\text { Accuracy/ } \\
\text { Stability } \\
(\%) \\
\end{array}$ \\
\hline $\begin{array}{l}\text { Aautosampler } \\
\text { stability } \\
\left(\text { at } 10^{\circ} \mathrm{C} \text { for } 35 \mathrm{~h}\right) \\
\end{array}$ & $\begin{array}{l}50.0 \\
6000\end{array}$ & $\begin{array}{l}47.4 \pm 3.87 \\
6042 \pm 206\end{array}$ & $\begin{array}{l}8.17 \\
3.41\end{array}$ & $\begin{array}{l}94.8 \\
101\end{array}$ \\
\hline $\begin{array}{l}\text { Wet extract stability } \\
\text { (at } 2-8^{\circ} \mathrm{C} \text { for } 32 \mathrm{~h} \text { ) }\end{array}$ & $\begin{array}{l}50.0 \\
6000\end{array}$ & $\begin{array}{l}46.9 \pm 1.55 \\
6133 \pm 204\end{array}$ & $\begin{array}{l}3.31 \\
3.32\end{array}$ & $\begin{array}{l}93.8 \\
102\end{array}$ \\
\hline $\begin{array}{l}\text { Bench top stability } \\
\text { (16 h at room } \\
\text { temperature) }\end{array}$ & $\begin{array}{l}50.0 \\
6000\end{array}$ & $\begin{array}{l}46.8 \pm 3.38 \\
5983 \pm 166\end{array}$ & $\begin{array}{l}7.22 \\
2.77\end{array}$ & $\begin{array}{l}93.6 \\
99.7\end{array}$ \\
\hline $\begin{array}{l}\text { Freeze-thaw } \\
\text { stability ( } 3 \text { cycles) }\end{array}$ & $\begin{array}{l}50.0 \\
6000\end{array}$ & $\begin{array}{l}47.3 \pm 2.39 \\
5871 \pm 315 \\
\end{array}$ & $\begin{array}{l}5.05 \\
5.37\end{array}$ & $\begin{array}{l}94.6 \\
97.9 \\
\end{array}$ \\
\hline $\begin{array}{l}\text { Reinjection stability } \\
(32 \mathrm{~h})\end{array}$ & $\begin{array}{l}50.0 \\
6000\end{array}$ & $\begin{array}{l}45.8 \pm 2.96 \\
5652 \pm 327\end{array}$ & $\begin{array}{l}6.46 \\
5.78\end{array}$ & $\begin{array}{l}91.5 \\
94.2\end{array}$ \\
\hline $\begin{array}{l}\text { Long-term } \\
\text { Stability (at } \\
-80^{\circ} \mathrm{C} \text { for } 40 \text { days) }\end{array}$ & $\begin{array}{l}50.0 \\
6000\end{array}$ & $\begin{array}{l}49.2 \pm 2.33 \\
6131 \pm 303\end{array}$ & $\begin{array}{l}4.74 \\
4.94\end{array}$ & $\begin{array}{l}98.3 \\
102\end{array}$ \\
\hline
\end{tabular}

\section{Conclusion}

The proposed LC-MS/MS assay is simple, rapid and sensitive for the determination of febuxostat in human plasma. The method describes the complete method development and validation process as per US FDA guidelines and is well suitable for pharmacokinetic or bioavailability/bioequivalence application. Simple PP extraction gives high and reproducible recovery febuxostat and the IS. Also, the method was rapid with run time of $2 \mathrm{~min}$ and alternative for existing methods for routine drug analysis. Thus, the advantage of this method is that a relatively large number of samples can be analyzed in short time, thus increasing the output.

\section{Acknowledgements}

The authors gratefully acknowledge PCR Laboratories (Hyderabad, India) for providing necessary facilities to carry out this work.

\section{References}

1. Ernst, M. E., \& Fravel, M. A. (2009). Febuxostat: a selective xanthine-oxidase/xanthinedehydrogenase inhibitor for the management of hyperuricemia in adults with gout. Clinical Therapeutics, 31(11), 2503-2518. doi:10.1016/j.clinthera.2009.11.033. 
2. Takano, Y., Hase-Aoki, K., Horiuchi, H., Zhao, L., Kasahara, Y., Kondo, S., \& Becker, M. A. (2005). Selectivity of febuxostat, a novel non-purine inhibitor of xanthine oxidase/xanthine dehydrogenase. Life Sciences, 76(16), 1835-1847. doi:10.1016/j.lfs.2004.10.031.

3. Khosravan, R., Grabowski, B. A., Wu, J. T., Joseph-Ridge, N., \& Vernillet, L. (2006). Pharmacokinetics, pharmacodynamics and safety of febuxostat, a non-purine selective inhibitor of xanthine oxidase, in a dose escalation study in healthy subjectsm. Clinical Pharmacokinetics, 45(8), 821-841. doi:10.2165/00003088-200645080-00005.

4. Luo, Z., Nan, F., Miao, J., Chen, Z., Li, M., \& Liang, M. (2016, March 14). Pharmacokinetics and bioequivalence of two formulations of febuxostat $40 \mathrm{mg}$ and $80 \mathrm{mg}$ tablets: A randomized, open-label, 4-way crossover study in healthy chinesemalevolunteers. PLoS One, 11(3), e0150661. doi:10.1371/journal.pone.0150661.

5. Vaka, V. R., Inamadugu, J. K., Pilli, N. R., Ramesh, M., \& Katreddi, H. R. (2013). A sensitive LCMS/MS method for the quantification of febuxostat in human plasma and its pharmacokinetic application. Biomedical Chromatography, 27(11), 1406-1412. doi:10.1002/bmc.2936.

6. Lukram, O., Parmar, S., \& Hande, A. (2013). Determination of febuxostat in human plasma using ultra-performance liquid chromatography tandem mass spectrometry. Drug Testing and Analysis, 5(6), 492-499. doi:10.1002/dta.420.

7. Wang, H., Deng, P., Chen, X., Guo, L., \& Zhong, D. (2013). Development and validation of a liquid chromatography-tandem mass spectrometry method for the determination of febuxostat in human plasma. Biomedical Chromatography, 27(1), 34-38. doi:10.1002/bmc.2744.

8. Ding, X., Zhang, Q., Wang, Z., \& Lin, G. (2012). Development and validation of liquid chromatography-mass spectrometry method for determination of febuxostat in rat plasma and its application. Latin American Journal of Pharmacy, 31, 321-325.

9. Matta, M., Pilli, N., \& Rao J.V.L.N, S. (2015). A validated liquid chromatography and tandem mass spectrometric method for simultaneous quantitation of tenofovir, emtricitabine and efavirenz in human plasma and its pharmacokinetic application. Acta Chromatographica, 27, 27-39. doi:10.1556/AChrom.27.2015.1.3.

10. Matta, M. K., Burugula, L., Pilli, N. R., Inamadugu, J. K., \& Jvln, S. R. (2012). A novel LC-MS/MS method for simultaneous quantification of tenofovir and lamivudine in humanplasma and its application to a pharmacokinetic study. Biomedical Chromatography, 26(10), 1202-1209. doi:10.1002/bmc.2679.

11. US DHHS. FDA and CDER. Guidance for Industry: Bioanalytical Method Validation. US Department of Health and Human Services, Food and Drug Administration, Center for Drug Evaluation and Research and Center for Veterinary Medicine, 2001. Available at: http://www/ fda.gov/cder/guidance/index.htm.

12. Krishna Matta, M., Rao Pilli, N., Kumar Inamadugu, J., Burugula, L., \& Rao JVLNS. (2012). Simultaneous quantitation of lamivudine, zidovudine and nevirapine in human plasma by liquid chromatography-tandem mass spectrometry and application to a pharmacokinetic study. Acta Pharmaceutica Sinica. B, 2(5), 472-480. doi:10.1016/j.apsb.2012.07.003.

13. Putluru, S. P., Matta, M. K., Ahire, D., Subramanian, M., Sinz, M., \& Mandlekar, S. (2017). A novel liquid chromatography tandem mass spectrometry method for the estimation of bilirubin glucuronides and its application to in vitro enzyme assays. Drug Metabolism Letters, 10(4), 264-269. doi:10.2174/1872312810666161124143522.

14. Adireddy V, Kovvasu SPR, Ravella VN. (2017). Simple and rapid LC-MS/MS method for the determination of rasagiline in human plasma, European Journal of Biomedical and Pharmaceutical Sciences, 4(11); 695-699.

15. Gandla, K., Repudi, L., \& Kovvasu, S. P. R., RaoRN. (2017). Simple and rapid determination of rosuvastatin inhuman plasma by LC-MS/MS. World Journal Pharmacy and Pharmaceutical Sciences, 6(11), 1027-1037. 